\title{
The assessment of leadership development in the medical undergraduate curriculum: a UK consensus statement
}

Dr Tim Swanwick, People Directorate, NHS England and NHS Improvement, Leeds, UK Professor Judy McKimm, College of Medicine, Swansea University, UK

\section{Keywords}

Assessment

Clinical leadership

Development

Leadership assessment

Student

\section{Corresponding author:}

Dr Tim Swanwick

Director of Clinical Leadership Development

People Directorate

NHS England and NHS Improvement

3 The Embankment

Sovereign St

Leeds LS1 4BJ

\section{E: tim.swanwick@leadershipacademy.nhs.uk}<smiles>[Te]</smiles>

Word count: 3010 


\section{The assessment of leadership development in the medical undergraduate curriculum: a consensus statement}

Dr Tim Swanwick and Professor Judy McKimm

\section{Summary}

With the increasing prominence of leadership within the medical undergraduate curriculum, assessment becomes a significant issue. In the absence of evidence to support specific strategies, tools or approaches, faculty from universities across the UK came together in October 2019 in a workshop convened by the Faculty of Medical Leadership and Management. The workshop aimed to develop a collective view on the assessment of leadership development in the medical undergraduate curriculum. This resulting consensus statement was generated around five prompts; why, what, how, when, and who? In addition to the statement's key messages, several questions for further exploration were defined. See Box 1.

\section{Box 1}

The assessment of leadership development in the medical undergraduate curriculum

\section{Key messages to support implementation}

- The Faculty of Medical Leadership and Management 'indicative curriculum' provides a blueprint of key leadership topics - knowledge, skills and professional behaviours - and how they might be assessed throughout the curriculum

- Portfolios, work-based observations and multisource feedback are useful tools to assess leadership development alongside incorporation of leadership as a specific domain within written assessments and clinical skills assessments

- Feedback on leadership behaviours can feel intensely personal and exposing; it should be delivered by someone skilled in feedback and pastorally aware

- Leadership development should be assessed longitudinally, throughout undergraduate programmes, and aligned with 'professionalism' teaching and learning

- The aspects of leadership to be assessed need to be measurable and relevant to the stage of education or training

- Assessment design decisions should involve leadership development expertise. Peers, near-peers and patients can all usefully be engaged in work-based assessment. 


\section{Key questions for further exploration}

- Schools vary considerable in their curriculum structure, ethos and delivery and will need, individually, to consider carefully how they incorporate assessment of leadership within the broader area of 'professionalism'.

- Students are forming their professional identities during medical school and may not see leadership as relevant to them. How do we ensure that leadership teaching and its assessment is meaningful to students?

- Whilst leadership has a strong theoretical basis, there is a risk of reductionism or idiosyncratically foregrounding one or two specific concepts. How can theory be meaningfully introduced in a way that is objective and balanced?

- Leadership is a social construct and we can only assume cognitive processes, values or personality traits and identity formation, from behaviours; how do we ensure that assessment (particularly summative) is balanced, fair and relevant to each stage of education?

- What kind of training or development do faculty need to help them deliver and assess this vitally important area of the undergraduate medical curriculum?

\section{Introduction}

Fundamental to the social accountability of medical schools is an undertaking for their programmes to be 'fit for purpose'. All doctors will assume a leadership role of some sort during their career, so making leadership learning and assessment explicit in the curriculum, with clear statements of intent, and weaving leadership development throughout the undergraduate programme, normalises leadership as a core clinical activity and prepares students for their future working lives.

In medical schools throughout the UK there is now a sustained effort to embed leadership and management in undergraduate programmes (1) with other countries - such as Australia, New Zealand and the US - beginning to follow suit. $(2,3)$ But this is not straightforward. Concerns remain about the place of leadership in a 'crowded curriculum', (4) surfacing leadership learning from the often muddy waters of professionalism can prove difficult (5); and the ability of faculty, both in university and practice settings, to meaningfully address the subject matter of leadership may be limited. Above all, universities 'require the flexibility to tailor their leadership development offer in line with the philosophy and structure of their undergraduate medical programmes'. (6)

Progress is, however, being made. In 2018 the Faculty of Medical Leadership and Management (FMLM) published an indicative undergraduate curriculum (7) based on a 'Medical Leadership Competency Framework' (8) drawn up almost 10 years previously. The curriculum is part of a wider programme of work to support the embedding of leadership in undergraduate medical programmes being led in partnership with the UK Medical Schools 
Council and the NHS Leadership Academy. Subsequent publications have provided further guidance and showcased best practice in student selected components, electives and intercalated degrees, and a national programme of faculty development including newsletters, webinars and workshops has addressed issues such as personality profiling, online learning and clinical placements. (9) To support implementation of the curriculum, FMLM has also established an accreditation scheme through which medical schools can be assessed against their ability to deliver the indicative leadership curriculum resulting in the award of an FMLM 'kitemark'. (10)

A key curriculum driver for medical schools is to meet the outcomes and standards set out by the General Medical Council (GMC). 'Leadership and team working' is now a key domain within Outcomes for Graduates (11) thus providing leverage for champions of leadership learning to press for its inclusion in the curriculum on regulatory grounds. But while the teaching of leadership may be relatively uncontentious, assessment remains challenging reflecting the generic challenge of assessment within all the domains of professionalism (12) - and high quality evidence as how best to assess this particular domain (leadership) at undergraduate level, non-existent.

\section{Consensus process}

This consensus statement derives from a workshop convened by the Faculty of Medical Leadership and Management on 3rd October 2019.

\section{Objectives}

The objectives of the workshop were to 'identify and select appropriately from the range of assessment methods that may be utilised in assessing leadership and management, recognise relevant theoretical and practical considerations, apply ideas and principles from the workshop in the development of their own assessment strategies, access a network of peers, expertise and best practice and to work together to generate a consensus statement on the assessment of leadership'.

\section{Participants}

The event brought together representatives from universities from across the UK together with practice educators, leadership developers, and representatives from the General Medical Council, business schools, other healthcare professions and the wider public sector. Invitations were extended to a list of self-designated curriculum 'leadership leads' from the faculty of universities across the UK. Each medical school was also invited to bring along colleagues who could be include teachers of quality or service improvement, professionalism and assessment leads. A full list of the 45 attendees, and their institutions, is provided in the acknowledgements of this paper.

\section{Building the consensus}

The workshop ran for a whole day with the objectives provided in advance to participants. Brief presentations initially established the context and drivers, specifically future clinical need, the expectations of the regulator (General Medical Council) and the current situation in 
medical schools. Participants were then invited, in collaboration, to surface challenges and issues. There followed a further interactive session during which participants rotated round a number of stations at which five medical schools shared their current leadership assessment practice with a specific focus on either knowledge, skills or behaviours. A panel presentation on leadership assessment in other public sector bodies, universities and professional leadership development programmes concluded the input for the day. The remainder of the workshop was spent in small groups considering the five questions laid out below followed by a plenary session during which participants were invited to review each other's work and distribute votes for the statements which they considered most important. Following the event, the authors (JM and TS) reviewed all written outputs taking into account the emphases ascribed by participants and collated these into a summary consensus statement. Feedback was subsequently sought, and received, from attendees before finalising the statement for publication.

\section{Key questions addressed}

Why assess leadership?

There are a number of reasons why leadership should be assessed at undergraduate level. From an individual student perspective, inclusion of leadership (alongside management and followership) helps to provide a more holistic and realistic preparation for professional practice and development. Because leadership development is very much about personal growth, longitudinal assessments can help unlock and activate student awareness; solidify learning; drive student learning and engagement; build a sense of achievement and development; grow self-awareness and self-insight, and develop a student's personal leadership approach, skills and style. The skills and insights gained through leadership assessment can thus enable students to take better control of their learning, and life, and for faculty, may help in identifying students who may need help and support, both now and in the future.

Finally, because assessment drives learning, if we don't assess, then we run the risk of leadership being crowded out of the curriculum by other more established disciplines and clinical specialties.

\section{What should we assess?}

If leadership is a process of social influence, occurring in a group context towards the achievement of a common goal (13) how should we approach this in the undergraduate context where students carry little, if any, managerial accountability?

As an underpinning body of knowledge, and to help students see the relevance of leadership to their practice, it is helpful to apply some theory and evidence to practice in ways that are meaningful at this stage of professional development. Assessment should then follow at a standard that is appropriate to level, in line with GMC requirements, and matched with later postgraduate expectations. 
Another major consideration is how to assess leadership within the more general domain of professionalism, ensuring that the distinct features of 'leadership' are included, whilst acknowledging that many aspects of leadership such as teamworking, reflective practice, organisational and system awareness and quality improvement are part of 'being and becoming' a professional. It is important therefore that leadership 'champions' work closely with professionalism leads to embed leadership within written and practical assessments of professionalism.

The FMLM 'indicative curriculum' provides a blueprint of key leadership topics and how they might be assessed throughout the curriculum. In structuring assessment, these topics need to be delineated into knowledge (e.g. the structure of the healthcare system), skills (e.g. project management, influencing skills), professional behaviours (e.g. teamworking) and personal development (e.g. self-awareness, resilience and emotional intelligence). The latter aspect is most challenging. Personal and professional values and attitudes (e.g. honesty, integrity) can manifest as leadership behaviours, including compassion and inclusion (two fundamental requirements) and assessments need to be developed to measure students' ability to recognise these behaviours in others and themselves.

\section{How should we assess?}

Factual knowledge can be summatively assessed through applied written knowledge tests (e.g. extended matching or single best answer) and application of knowledge through project reports, case studies, essays, significant event analyses, reflections on workplace observations and/or their own practice, or application of leadership models or frameworks to practice. Training will be required to prepare students for assessment using these different modalities.

Portfolio assessments can provide the basis for more longitudinal developmental assessment, and assessors should consider the absence of negative indicators as well as positive evidence of effective leadership (and the related areas of management and followership).

Leadership skills can be assessed in practical assessments such as the OSCE (summative) or simulations (formative or summative); both particularly helpful vehicles when it comes to capabilities such as team working. Again, working with 'professionalism' colleagues on the domain will help identify how leadership can be woven into such assessments, considering aspects such as management of specific clinical situations (e.g. knowing when to lead, when to follow) and communication skills.

Work-based observations (e.g. direct observations of skills) using fragments of work (e.g. leading part of a ward round) as the substrate to test leadership behaviours and multisource, or 360 , feedback are probably the most authentic ways to assess leadership in practice. As mentioned above, formative assessments and feedback on leadership development and skills in practice should be punctuated by summative assessments. Multisource feedback is also very helpful from other members of the healthcare team. Higher stakes summative assessment of leadership, management and followership (in relation to 
teamworking, self-management and prioritisation for example) should be carried out by workplace assessors who are appropriately trained and aligned in approach.

Because feedback on leadership performance (because of its intensely personal nature) is exposing and potentially confronting, it should be discussed with someone expert in feedback and pastorally aware. If a portfolio is used which gathers multiple perspectives from assessors, then (particularly if the feedback is less than positive) a person with whom the student has an ongoing relationship e.g. a mentor, might be more appropriate. Multiple perspectives can helpfully contribute to a portfolio of evidence collected across the continuum of basic medical education but, to be useful for the student's own leadership development, should be approached in a similar longitudinal way to how the educational supervisor role is conceptualised in postgraduate medical education.

\section{When should we assess leadership?}

Assessment of leadership capabilities should start early and be underpinned by relevant conceptual frameworks.

Assessment should also be continuous, longitudinal and integrated - every learning event has leadership development potential - and take a spiral approach to reflect the ongoing acquisition of complex skills, application of knowledge and personal development. Care must be taken to ensure that aspects of leadership, management and followership are measurable and relevant to the stage of training/education

A combination of both formative and summative assessment should be used, and schools will need to determine the balance between them. We suggest that formative assessment should run throughout the programme, whereas summative assessment in leadership specifically (as opposed to 'professionalism' assessments) would seem to be particularly relevant for assessing knowledge in the early stages of the programme, and skills and behaviours towards the end as students prepare for the next stage of their education and training.

If reflection is to form a major element of assessment, then students will require support in relation to frameworks to help them reflect and what constitutes 'good' reflective' writing. For leadership aspects that relate more to personal development, much of the assessment will need to be formative. And, as with all assessment, but particularly important for those subjects that lie in the professionalism domain, where students are underperforming there should be clear processes for remediation.

On entry into postgraduate training, assessments such as situational judgement tests, where there are no absolute right and wrong answers, provide an ideal opportunity to further embed targeted questions on leadership, itself a practice rich with nuanced decision-making.

\section{Who should assess?}

The assessment of leadership knowledge will require faculty to have a grasp of the field themselves. As this is a somewhat specialised area that requires teasing out from the 
related but distinct domain of professionalism, a designated leadership curriculum lead is recommended.

Leadership leads will need to work with clinical skills leads and other staff involved in running OSCEs or simulations to advise on aspects specifically concerned with practical leadership skills. Assessment of leadership in relevant situations can be carried out by academic and clinical faculty (including doctors and other health professionals), peers, near-peers and patients, trained in assessment and feedback.

In a similar way to assessment of practical skills, workplace assessment of leadership behaviours can be carried out routinely and formatively by a wide range of faculty, peers and patients. Peer-assessment by other students and/or doctors in training is probably most appropriate in team-based or group work settings, through multisource feedback.

\section{Discussion}

The consensus generated above only takes us so far, and in the process of arriving where we have, a number of issues for further exploration were also surfaced.

The first is the relationship between 'professionalism' and 'leadership' teaching, learning and assessment. This will largely be resolved at local level, being dependant on the structure, ethos and delivery of the curriculum, the influence and expertise of the various leads and the way in which professionalism is currently learned, taught and assessed.

Secondly, as with professionalism (14), we are addressing three discourses in defining 'leadership', as:

- an individual characteristic, trait, behaviour or cognitive process

- an interpersonal process or effect

- a socially constructed way of acting or being

Medical students are in the process of developing their medical professional identities, which may or may not include seeing themselves as leaders. These factors and discourses pose a fundamental challenge with an inherent tension. Assessments (particularly if summative) need to be able to specify 'acceptable' and 'unacceptable' leadership behaviours, so that these can be measured. However, such behaviours are socially constructed, vary across cultures and times, and therefore assessments tend to be subjective. We can only assume cognitive processes, values or personality traits and identity formation from behaviours and observation of the impact of one individual 'leader' on others often struggles to take account of underpinning factors of influence.

Thirdly, whilst it is helpful that the in the UK, the GMC (in Outcomes for Graduates) has recognised that leadership development has a theoretical base, this raises a host of issues for further exploration. For example, which of the myriad of leadership theories, concepts and models would we deem appropriate for students to learn about to the extent that they could be summatively assessed upon? Because the curriculum is so crowded, there is also a real risk of reductionism e.g. a foregrounding of one or two models. In a rapidly evolving, socially constructed area such as leadership, summative assessment on theories and 
concepts may feel inappropriate. This also relates to the stages of training in that there might be identifiable 'stages' of leadership learning that might be more appropriate (say) to Year 5 than Year 1.

The fourth question surrounds achieving an appropriate balance between summative and formative assessment. This is particularly pertinent in the context of high-stakes assessments such as standardised licensing assessments and it is important therefore that the leadership 'voice' is involved in the development and implementation of assessment items that involve leadership.

Finally, the costs and benefits of training and maintaining an informed and skilled faculty need to be identified, alongside the kind of training that faculty need to help them deliver and assess this vitally important area of the undergraduate medical curriculum.

\section{Conclusion}

Consensus statements are the articulation of a collective opinion on a specific issue from those working in the field. Readers 'must assess the quality and validity of consensus statements as they do for all literature'.(15) As is the case here, the consensus process often generates more questions than answers. Such questions may provide useful direction for future research, but in its absence, we hope that this statement, and its key messages will prove useful.

\section{Contributorship}

JMcM and TS conceived the workshop, facilitated the discussion and produced a first draft of the statement. Following feedback from participants both authors contributed to the revised statement and collaborated on subsequent responses to editorial comments.

\section{Funding}

N/A

\section{Competing interests}

None

\section{Acknowledgements}

Contributors to the workshop held on 3 October 2019 in London, UK: Packianathaswamy Balaji (Hull York Medical School), Claire Blandford (University of Exeter Medical School), Tom Bourke (Queen's University Belfast), Charlie Brown (Staff College), Pauline Bryan (Norwich Medical School), Fiona Butt (Leeds University), Ben Chadwick (University of Southampton Faculty of Medicine), Suzanne Chamberlain (GMC), Ann Chapman, Gaurish 
Chawla, (Brighton and Sussex Medical School), Kwok-Leung Cheung (University of Nottingham), Sethi Cindy (KCL), Jane Day (ARU), Laura Evans (NHS Leadership Academy), Jon Fistein (University of Cambridge), Faye Gishen (UCL Medical School), Francesca Hall (Brighton and Sussex Medical School), Kamila Hawthorne (Swansea University), Kevin Hayes (St George's University London), Claire Hobson (FMLM) Judith Ibison (St George's university of London), Steve Jones (Newcastle University) Paul Jones (Swansea University), Daniel Kent, (University of Nottingham), David Lilley (Staff College), Siobhán Lynch (University of St Andrews), Ann Mahon (Manchester University), Zoe McElhinney (University of Dundee), Judy McKimm (Swansea University) Pat Owen (Keele University), David Raw (University Of Liverpool), Karen Rogstad (University of Sheffield Medical School), Cindy Sethi (KCL), Sangeetha Sornalingam, Catherine Swales (Oxford University), Tim Swanwick (NHS Leadership Academy), Simon Tavernor (School of Medicine, University of Liverpool), Vicki Tully (University of Dundee), Pirashanthie Vivekananda-Schmidt (University of Sheffield), Deirdre Wallace (University College London), Kirsteen Watson (University of Cambridge School if Clinical Medicine), Judith West (University of Leicester).

\section{References}

1. Till A, McKimm J and Swanwick T. The Importance of Leadership Development in Medical Curricula: A UK Perspective (Stars are Aligning). J Healthc Leadersh. 2020;12:19-25

2. Lyons O, McHardy K, Bagg W et al. Leadership development in New Zealand and Australian medical schools: needs analysis BMJ Leader 2019;3:123-128.

3. Webb AM, Tsipis NE, McClellan TR et al. A first step toward understanding best practices in leadership training in undergraduate medical education: a systematic review. Acad Med. 2014;89(11):1563-1570.

4. Jefferies R, Sheriff IHN, Matthews JH et al. Leadership and management in UK medical school curricula. Journal of Health Organization and Management. 2016;30(7):1081-1104.

5. Hardy LJ and Neve H. Professionalism and leadership in medical education: how do they differ and how are they related? BMJ Leader 2019;3:67-68

6. Till A, McKimm J and Swanwick T. Twelve tips for integrating leadership development into undergraduate medical education. Medical Teacher. 2017;40:1-7.

7. Peake L, Spurgeon P, McKimm J et al. Medical leadership and management. An indicative undergraduate curriculum. London: Faculty of Medical Leadership and Management, 2018.

8. Academy of Royal Medical Colleges and NHS Institute for Innovation and Improvement. Medical Leadership Competency Framework. London: NHS Institute of Innovation and Improvement, 2008.

9. Faculty of Medical Leadership and Management Resources for medical school faculty www.fmlm.ac.uk/careers/students/resources-for-medical-school-faculty, accessed 28 May 2020. 
10. Faculty of Medical Leadership and Management. Accredit your undergraduate curriculum for medical leadership, www.fmlm.ac.uk/accredit-your-undergraduate-curriculumfor-medical-leadership, accessed 26 February 2020.

11. General Medical Council. Outcomes for Graduates. GMC, London, 2018.

12. Li H, Ding N, Zhang $Y$ et al. Assessing medical professionalism: A systematic review of instruments and their measurement properties. PLoS One. 2017;12(5):e0177321.

13. Northouse P. Leadership: Theory and Practice, 3rd edn. Sage, London, 2004.

14. Hodges BD, Ginsburg S, Cruess R et al. Assessment of professionalism:

recommendations from the Ottawa 2010 Conference. Med Teach. 2011;33(5):354-363.

15. Olson CM. Consensus Statements: Applying Structure. JAMA. 1995;273(1):72-73. 